\title{
The relative risk of the toxico-clinical parameters based on poisoning severity and outcomes in patients with acute poisoning
}

Nastaran Eizadi-Mood

Isfahan University of Medical Sciences

Rasol Heshmat

Isfahan University of Medical Sciences

Rokhsareh Meamar ( $\nabla$ meamar@pharm.mui.ac.ir)

Isfahan University of Medical Sciences

Narges Motamedi

Isfahan University of Medical Sciences

\section{Research Article}

Keywords: Severity Score, Poisoning, Outcome, Complication, epidemiology, death

Posted Date: May 12th, 2021

DOl: https://doi.org/10.21203/rs.3.rs-464174/v1

License: (c) (i) This work is licensed under a Creative Commons Attribution 4.0 International License.

Read Full License 
The relative risk of the Toxico-clinical parameters based on poisoning severity and 1 \begin{tabular}{l|l} 
outcomes in patients with acute poisoning & 2
\end{tabular}

Nastaran Eizadi-Mood ${ }^{1}$, Rasol Heshmat ${ }^{2}$, Rokhsareh Meamar ${ }^{3}$, Narges Motamedi ${ }^{4}$, 4

1- Professor, Department of Clinical Toxicology, School of Medicine, Isfahan Clinical 5 Toxicology Research Center, Isfahan University of Medical Sciences, Isfahan, Iran. 6

$\begin{array}{ll}\text { Email: izadi@ med.mui.ac.ir } & 7\end{array}$

2- General Physician, Department of Clinical Toxicology, School of Medicine, Isfahan 8

University of Medical Sciences, Isfahan, Iran. $\quad 9$

E-mail: heshmatrasol@gmail.com 10

3- Assistant Professor, Isfahan Clinical Toxicology Research Center, Isfahan University of 11

Medical Sciences, Isfahan, Iran. E-mail: meamar@pharm.mui.ac.ir 12

4- Assistant Professor, Department of Community \& Preventive Medicine, School of 13 Medicine, Isfahan University of Medical Sciences, Isfahan, Iran. Email: 14 n_motamedi@med.mui.ac.ir $\quad 15$

*Corresponding author: Dr. Rokhsareh Meamar, Isfahan Clinical Toxicology Research 17

Center, Khorshid Hospital, Ostandari Street, Hasht Behest Avenue, Isfahan, Iran Postal code: 18

81458-31451Ｅ-mail:meamar@pharm.mui.ac.ir 19 
$\begin{array}{ll}\text { Abstract } & 1\end{array}$

Background: Identification of complications or death risk factors in patients with acute 2 poisoning allows better monitoring and treatment. Hence, the aim of this study was to 3 determine the relative risk of toxico-clinical parameters based on poisoning severity and 4 outcomes in patients with acute poisoning. $\quad 5$

Methods: This cross-sectional study consisted of patients with acute poisoning admitted to the 6 poisoning emergency room from 2018 to 2019. Patients were categorized into four groups 7 minor, moderate, severe, and fatal poisoning. Different toxico-clinical parameters were 8 analyzed by multivariate logistic regression. $\quad 9$

Results: The most common poisoning in the minor group was opioids, alcohols, and 10 benzodiazepine (14.7\%), in the moderate and severe groups was multidrug (23.3\%) and in the 11 fatal group pesticides poisoning (23\%). Pre-hospital antidote administration (OR, 7.08; P- 12 value, 0.006); low level of consciousness (OR, 4.38; P-value, 0.001); abnormal ECG (OR, 13 4.56; P-value, 0.003); and time interval of intoxication to admission in the hospital (OR, 1.15; 14 P-value, 0.01) were the predictive factors for poisoning severity. 15 $49.7 \%$ of patients recovered without any complications. Patients with low level of 16 consciousness (OR, 66.06; P-value, 0.01); underlying disease (OR, 3.65; P-value, 0.03); 17 abnormal respiration (OR, 1.14; P-value, 0.02); and longer duration of hospitalization (OR, 18 1.02; P-value, 0.001) had greater risk of complications/ Death. 19 Conclusions: In clinical practice, low level of consciousness, pre-hospital antidote 20 administration, abnormal ECG, underlying disease, abnormal respiration, delay to presentation 21 to hospital, and longer length of hospital stay can be considered important factors for 22 determining poisoning severity and outcome. 23 Key words: Severity Score, Poisoning, Outcome, Complication, epidemiology, death 24 
Acute poisonings are one of the important medical emergencies considered as an epidemic 2 worldwide (1). In Asian countries, more than $60 \%$ of all deaths are occurred due to 3 intoxication(2). In developing countries, the incidence of poisoning is forecasted to be greater 4 than in developed countries due to a lack of monitoring systems with incomplete regulations, 5 an absence of training, insufficient availability of information systems, and large agricultural- 6 based populations(3) .

During the past 10 years, the American Association of Poison Control Centers reported that 8 antidepressant overdose increased most rapidly by $7.02 \%$ per year showing more serious 9 outcomes (4). Estimations based on a systematic review showed that 385 million cases of unintentional, acute pesticide poisoning happen annually worldwide consisting of around 11,000 mortalities (5).

Clinicians with recommended criteria could predict disease outcomes, qualitative assessment of the disease, and evaluation of poisoning pattern in patients (6-8). Poisoning Severity Score (PSS) is one of the criteria reported by Persson et al. in 1998 (9). It has been presented that PSS is effective in identifying the severity of intoxication $(9,10)$. Some factors have been associated with the severity of poisoning including age, intentional poisoning, respiratory and circulatory failure, unresponsiveness, and seizures (11-13). In addition, electrocardiographic signs $(14,15)$ and biochemical markers also linked with poisoning severity (12). Identification of complications or death risk factors in poisoning patients allows more intensive 20 monitoring and treatment. Usually, the different scoring systems used in the emergency room selecting patients for the intensive care unit. However, some epidemiological and toxicological 22 variables which may affect the severity and outcome of the poisoning patients, have not been 23 included in these scoring systems. Therefore, the aim of this study was to describe the relative 
risk of toxico-clinical parameters on poisoning severity and outcomes in patients with acute poisoning.

Methods

This cross-sectional study was conducted in the referral poisoning emergency center of the province. The inclusion criteria consisted of patients with acute poisoning admitted to the poisoning emergency room from 2018 to 2019 . Clearance with personal consent, asymptomatic 6 patients, and the lack of sufficient data on the medical file were exclusion criteria. The severity 7 of poisoning was determined based on the variables in the poisoning severity score (PSS) (9). 8 Data were obtained from a review of the case notes of the emergency physicians. Chart 9 abstractor (second author) trained before the study starts, using a set of "practice" medical 10 records. Patients were categorized into four groups; minor, moderate, severe, and fatal poisoning. The sample size was determined 300 patients using the confidence interval 95\%; $\mathrm{Z} 2=0.55$, Test power factor $80 \%$ (75 patients in each group). The sampling method was nonprobability consecutive samplings. Demographic data ( age, gender, marital status); the history of drug abuse; previous medical or psychiatric history; type of poisoning; route of exposure; kind of substance; time to admission; clinical manifestations; electrocardiogram

(ECG) changes; therapeutic modalities (pre-hospital and in-hospital gastrointestinal decontamination, administration of antidote); endotracheal intubation at the time of admission and within 24 hours of admission; length of hospital stay and outcome of the patients (recovery without complication, recovery with complications, and death were recorded in the data 20 collection form. We ensured the uniform handling of the data collection with the consensus meetings. Also, periodic meetings with the chart abstractor (second author) and study 22 coordinators (Corresponding author and First author) were held to resolve disputes and review coding rules. The performance of the chart abstractors was monitored by the corresponding author of the research project. 
Data are presented as mean \pm standard deviation $(\mathrm{SD})$ or standard error $(\mathrm{SE})$, median; and frequency (percentage) as appropriate. We used chi-square/Fisher exact tests and ANOVA for 2 analysis. Also, multivariate logistic regression analysis was employed to calculate the odds ratio $(\mathrm{OR})$ as the estimate of the relative risk of the different variables for the poisoning severity and outcomes. Complications and death combined as a single ordinal variable, comprising two possible outcomes: (0) recovery without complication, (1) complication/death. The P-value 6 less than 0.05 were considered statistically significant. All statistical analyses were conducted using SPSS software version 15 (SPSS Inc. Chicago USA).

Out of 300 patients studied, $63.7 \%$ were male, $37.0 \%$ were single, $16.6 \%$ had a previous underlying disease, and $34.7 \%$ had a history of psychiatry problems. The mean age (SD) of the patients was $34.1 \pm 15.43 .33 .0 \%$ of patients were addicted. Oral consumption $(89.0 \%)$ was the benzodiazepine $(14.7 \%)$ in the minor group, multi-drugs poisoning $(23.3 \%)$ in moderate and severe poisoning, and pesticides poisoning (23\%) in the fatal group. Details of toxico-clinical characteristics and treatment modalities with respect to poisoning severity are presented in

Tables 1 and 2. Men had more severe and fatal poisoning compared with women. We analyzed kind of substance between the two genders was detected (P- Value <.0001). Indeed, the most tendencies in males were indicated for opioids and pesticides (75\%) and among women for psychotropic agents $(84.6 \%)$.

The results of multivariate logistic regression to explore factors associated with the severity of 
admission in the hospital were identified as independent factors associated with the severity of poisoning. 149 recovered without complication (49.7\%). One patient in the minor group found 2 a complication. Twenty-three and 52 patients in moderate and severe poisoning groups 3 respectively developed complications during hospitalization. Table 4 reveals the results of 4 multivariate logistic regression to explore factors associated with outcome 5 (complications/Death). Duration of hospitalization, kind of substance, the level of 6 consciousness, respiratory rate, and underlying disease was identified as an independent factor 7 associated with complications/death.

Our study provides information on the toxico-clinical characteristics of patients based on the severity of poisoning and its relationship with outcome. The results showed the severity of poisoning (fatal) increased with age similar to other studies $(16,17)$. Also, the frequency of severe poisoning was higher in men compared with women. The reason may be due to intentional and higher pesticide poisoning in men which may have high mortality. Some studies also showed a higher mortality rate in men $(18,19)$. In a study related to the trend of fatal poisoning from 1990 to $2015,40,586$ deaths due to poisoning were estimated and from 1998 to 2015 , also the fatal cases were mostly in men (20).

In our study, similar to the other study the majority of fatal poisoning was related to suicide attempts (21). Overdoses are reasons for one-fourth of all suicide attempts (22). Psychiatric disorders are one of the more important factors that will be influenced by acute poisoning (1). epidemiological study reported $49.8 \%$ of patients had psychiatric disorders (23). The prevalence of mental health problems, low prices, and easy access to psychological prescription drugs have made psychological drug abuse a common phenomenon in urban areas (24). 
Poisoning with multidrug, pesticides, and opiates were common in severe to fatal groups. But, 1 ethanol or drugs were the most common cause of poisoning in industrialized countries (23). A 2 review study on acute poisoning in adults showed that drug combinations were the most 3 common causes of acute poisoning (25). Cultural differences and access to different drugs in 4 communities can explain this difference. In fact, drug and chemical poisoning is largely 5 $\begin{array}{lr}\text { influenced by socio-economic and socio-cultural factors. } & 6\end{array}$ The results showed that pesticide poisoning was a predictive factor of outcomes in our 7 population. But the large odds ratio may reduce the strength of this association in clinical 8 practice. We did not analyze data based on the different pesticides. Aluminum phosphide, 9 paraquat, and organophosphate poisoning are the most common pesticide intoxication in our 10 society. Since there is no definite treatment for aluminum phosphate and paraquat poisoning, 11 the mortality is higher in these pesticides compared to other pesticides (26). Death due to 12 pesticide poisoning in our study was $66.7 \%$ which is higher when compared to epidemiology reported from developing countries (21\% in South-East Asia)(22). However, another study (17) presented that intoxications by opiates, cocaine, and amphetamine had the highest mortality after ICU admission (12.3\%). Evaluating demographic differences in suicidal behavior is imperative for the improvement of specific service provisions in EDs (27). However, Jang et al, (29) presented a significant rising in mortality in patients with prolonged 20 QTc intervals. Also, prolonged QTc interval was a poor indicator for prognosis in 21 organophosphate poisoning in another study (30). Different results were presented concerning 
abnormal ECG changes (changes in rate and rhythm) had greater odds of severity poisoning

although we did not categorize them based on the type of abnormality in ECG.

2

Decreased level of consciousness state was also the important factor that predicted both 3 severities as well as the outcome of the poisoning. Although we did not determine the level of 4 consciousness based on the Glasgow Coma Scale (GCS), a significant correlation has been 5 observed between the GCS and PSS scores in another study (28). PSS and GCS were effective 6 tools for the determination of the severity of organophosphate poisoning(28). Davies et al. (32) described a similar effect for PSS and GCS in predicting mortality among patients with 8 organophosphate poisoning.

The time interval from poisoning to admission in the hospital was identified as another 10 independent factor associated with the severity of poisoning as well as the outcome. Alanazil (33) presented that among toddlers with delayed arrival times, more severe outcomes particularly in the respiratory, gastrointestinal, muscular, nervous, and kidney problems had been reported. This time is important regarding the efficiency of emergency department treatments, especially administering antidotes. Furthermore, a delayed arrival time over the three hours significantly influences the length of hospital stay (34). Delayed time is highly dependent on the issue of witnessing the occurrence of poisoning. Emergency department admission should be performed immediately when a suspected poisoning happened (35). Delaying in a treatment help to elevation drug initial peak serum level, consequently, leads to irreversible tissue damage. Sam et al. (6) found a linear correlation between those two 20 parameters as well, although they reported that clinical outcome will not influence by this duration. 
compared to others. And the only treatment statistically associated with a favorable outcome was antidote administration.

\section{Conclusions}

In clinical practice, low level of consciousness, pre-hospital antidote administration, abnormal ECG, underlying disease, abnormal respiration, delay to presentation to hospital, and longer length of hospital stay can be considered important factors for determining poisoning severity society.

Declarations

Ethics approval and consent to participate: This research has been performed in accordance informed consent was obtained from the patients (or their parent or legally authorized representative in the case of children under 16).

Consent for publication: Not applicable

Availability of data and materials: The datasets generated and/or analyzed during the current study are not publicly available due to the nature of patients who attempted suicide but are available from the corresponding author on reasonable request.

Competing interests: The authors declare that they have no competing interests.

Funding: The protocol was supported financially by the Isfahan University of Medical 
Authors' contributions: Nastaran Eizadi-Mood, Rokhsareh Meamar, and Rasol Heshmat

contributed to the conception and design of the study. Narges Motamedi and Nastaran Eizadi-

2

Mood interpreted the data. Nastaran Eizadi-Mood, Rokhsareh Meamar, and Rasol Heshmat

3

have drafted the work. All authors approved the submitted version (and any substantially

modified version that involves the author's contribution to the study); AND have agreed both

to be personally accountable for the author's own contributions and to ensure that questions

6

related to the accuracy or integrity of any part of the work, even ones in which the author was

7

not personally involved, are appropriately investigated, resolved, and the resolution 8

documented in the literature.

9

Acknowledgements: We would like to thank the colleagues and personnel of the Clinical 10 Toxicology Department and archive staff of Khorshid hospital for their valuable technical help 11 and general support. 
3. Wang N, Jiang Q, Han L, Zhang H, Zhu B, Liu X. Epidemiological characteristics of pesticide poisoning in Jiangsu Province, China, from 2007 to 2016. Scientific reports. 2019;9(1):1-8.

4. Gummin DD, Mowry JB, Spyker DA, Brooks DE, Beuhler MC, Rivers LJ, et al. 2018 Annual Report of the American Association of Poison Control Centers' National Poison Data System (NPDS): 36th Annual Report. Clinical toxicology. 2019;57(12):1220-413.

5. Boedeker W, Watts M, Clausing P, Marquez E. The global distribution of acute unintentional pesticide poisoning: estimations based on a systematic review. BMC public health. 2020;20(1):1-19.

6. Sam KG, Kondabolu K, Pati D, Kamath A, Kumar GP, Rao PG. Poisoning severity score, APACHE II and GCS: effective clinical indices for estimating severity and predicting outcome of acute organophosphorus and carbamate poisoning. Journal of forensic and legal medicine. 2009;16.239-47:(5)

7. Balci C, Sungurtekin H, Gürses E, Sungurtekin U. APACHE II, APACHE III, SOFA scoring systems, platelet counts and mortality in septic and nonseptic patients. Ulusal travma ve acil cerrahi dergisi $=$ Turkish journal of trauma $\&$ emergency surgery :TJTES. 2005;11(1):29-34.

8. Asadzandi M, Karati KT, Tadrisi SD, Ebadi A. Estimation of the mortality rate using the APACHE II standard disease severity scoring system in intensive care unit patients. Iranian Journal of Critical Care Nursing (IJCCN). 2012.209-14:(4)4; Grading of acute poisoning. Journal of Toxicology: Clinical Toxicology. 1998;36(3):205-13.

11. Lee H-L, Lin H-J, Yeh ST-Y, Chi C-H, Guo H-R. Presentations of patients of poisoning and predictors of poisoning-related fatality: findings from a hospital-based prospective study. BMC Public health. 2008;8(1):1-9.

12. Camilleri R, editor Analysis of risk factors that predict severity of acute poisoning. CLINICAL TOXICOLOGY; 2015: TAYLOR \& FRANCIS LTD 2-4 PARK SQUARE, MILTON PARK, ABINGDON OR14 4RN, OXON....

13. Yu J-H, Weng Y-M, Chen K-F, Chen S-Y, Lin C-C. Triage vital signs predict inhospital mortality among emergency department patients with acute poisoning: a case control study. BMC health services research. 2012;12(1):1-8.

14. Yates C, F Manini A. Utility of the electrocardiogram in drug overdose and poisoning: theoretical considerations and clinical implications. Current cardiology reviews. 2012;8(2):137-51.

15. Manini AF, Nelson LS, Skolnick AH, Slater W, Hoffman RS. Electrocardiographic predictors of adverse cardiovascular events in suspected poisoning. Journal of Medical Toxicology. 2010;6(2):106-15.

16. Brandenburg R, Brinkman S, De Keizer NF, Kesecioglu J, Meulenbelt J, de Lange DW. The need for ICU admission in intoxicated patients: a prediction model. Clinical toxicology. 2017;55(1):4-11.

17. Brandenburg R, Brinkman S, De Keizer NF, Meulenbelt J, De Lange DW. In-hospital mortality and long-term survival of patients with acute intoxication admitted to the ICU. Critical care medicine. 2014;42(6):1471-9.

18. Jiang G, Choi BC, Wang D, Zhang H, Zheng W, Wu T, et al. Leading causes of death from injury and poisoning by age, sex and urban/rural areas in Tianjin, China 1999-2006. Injury. 2011;42(5):501-6.

19. Krakowiak A, Piekarska-Wijatkowska A, Kobza-Sindlewska K, Rogaczewska A, Politański P, Hydzik P, et al. Poisoning deaths in Poland: types and frequencies reported in 
Łódź, Kraków, Sosnowiec, Gdańsk, Wrocław and Poznań during 2009-2013. International

20. Ghodsi Z, Moghaddam SS, Saadat S, Yoosefi M, Rezaei N, Ostadrahimi H, et al.

Trend of fatal poisoning at national and provincial levels in Iran from 1990 to 2015. Public 4 health. 2019;170:78-88.

21. Bagheri P, Sepand M. A meta analytical study of intentional and accidental non-food poisoning incidences in Iran (1991-2013). Koomesh. 2015;16(3):443-53.

22. Gunnell D, Ho D, Murray V. Medical management of deliberate drug overdose: a 8 neglected area for suicide prevention? Emergency Medicine Journal. 2004;21(1):35-8.

23. Resiere D, Kallel H, Oxybel O, Chabartier C, Florentin J, Brouste Y, et al. Clinical 10 and epidemiological characteristics of severe acute adult poisoning cases in Martinique: 11 implicated toxic exposures and their outcomes. Toxics. 2020;8(2):28. 12

24. Koskela L, Raatiniemi L, Bakke HK, Ala-Kokko T, Liisanantti J. Fatal poisonings in 13 Northern Finland: causes, incidence, and rural-urban differences. Scandinavian journal of 14 trauma, resuscitation and emergency medicine. 2017;25(1):90. 15

25. Alinejad S, Zamani N, Abdollahi M, Mehrpour O. A narrative review of acute adult 16 poisoning in Iran. Iranian journal of medical sciences. 2017;42(4.327:( 17

26. Alnasser S, Hussain SM, Kirdi TS, Ahmed A. Aluminum phosphide poisoning in 18 Saudi Arabia over a nine-year period. Annals of Saudi medicine. 2018;38(4):277-83. 19

27. Ala A, Vahdati SS, Moosavi L, Sadeghi H. Studying the Relationship Between Age, 20 Gender and Other Demographic Factors with the Type of Agent Used for Self-Poisoning at a 21 Poisoning Referral Center in North West Iran/Kuzey Bati Iran'da Bir Zehirlenme Referans 22 Merkezinde Kendini Zehirlemek için Kullanilan Ajan Tipi ile Yas, Cinsiyet ve Diger 23 Demografik Faktörlerin Iliskisinin Arastirilmasi. Eurasian Journal of Emergency Medicine. $\quad 24$ 2011;10(3):100.

28. Akdur O, Durukan P, Ozkan S, Avsarogullari L, Vardar A, Kavalci C, et al. 26 Poisoning severity score, Glasgow coma scale, corrected QT interval in acute 27 organophosphate poisoning. Human \& experimental toxicology. 2010;29(5):419-25. 28

29. Jang S, Lin J, Chuang F. Electrocardiographic findings of organophosphate 29 intoxication in emergency department as predictors of prognosis: a retrospective analysis . $\quad 30$ Changgeng yi xue za zhi. 1995;18(2):120.

30. Ludomirsky A, Klein HO, Sarelli P, Becker B, Hoffman S, Taitelman U, et al. QT 32 prolongation and polymorphous ("torsade de pointes") ventricular arrhythmias associated 33 with organophosphorus insecticide poisoning. The American journal of cardiology. 34 1982;49(7):1654-8.

31. Karki P, Ansari JA, Bhandary S, Koirala S. Cardiac and electrocardiographical 36 manifestations of acute organophosphate poisoning. Singapore medical journal. 37 2004;45(8):385-9. 38

32. Davies JO, Eddleston M, Buckley NA. Predicting outcome in acute 39 organophosphorus poisoning with a poison severity score or the Glasgow coma scale. QJM: $\quad 40$ An International Journal of Medicine. 2008;101(5):371-9.

33. Alanazi MQ, Al-Jeraisy M, Salam M. Severity scores and their associated factors 42 among orally poisoned toddlers: a cross sectional single poison center study. BMC pharmacology and toxicology. 2016;17(1):1. 44

34. Satar S, Seydaoglu G. Analysis of acute adult poisoning in a 6-year period and factors 45 affecting the hospital stay. Advances in therapy. 2005;22(2):137-47. 46

35. Alanazi MQ, Al-Jeraisy MI, Salam M. Comparative outcome analysis of home- 47 initiated non-medical interventions among toddlers with orally ingested substances. Italian 48 journal of pediatrics. 2015;41(1:(63). 